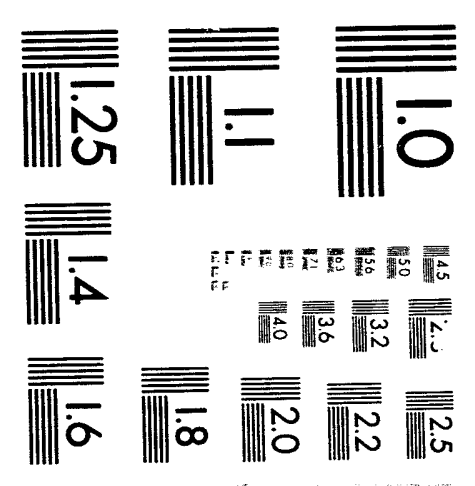



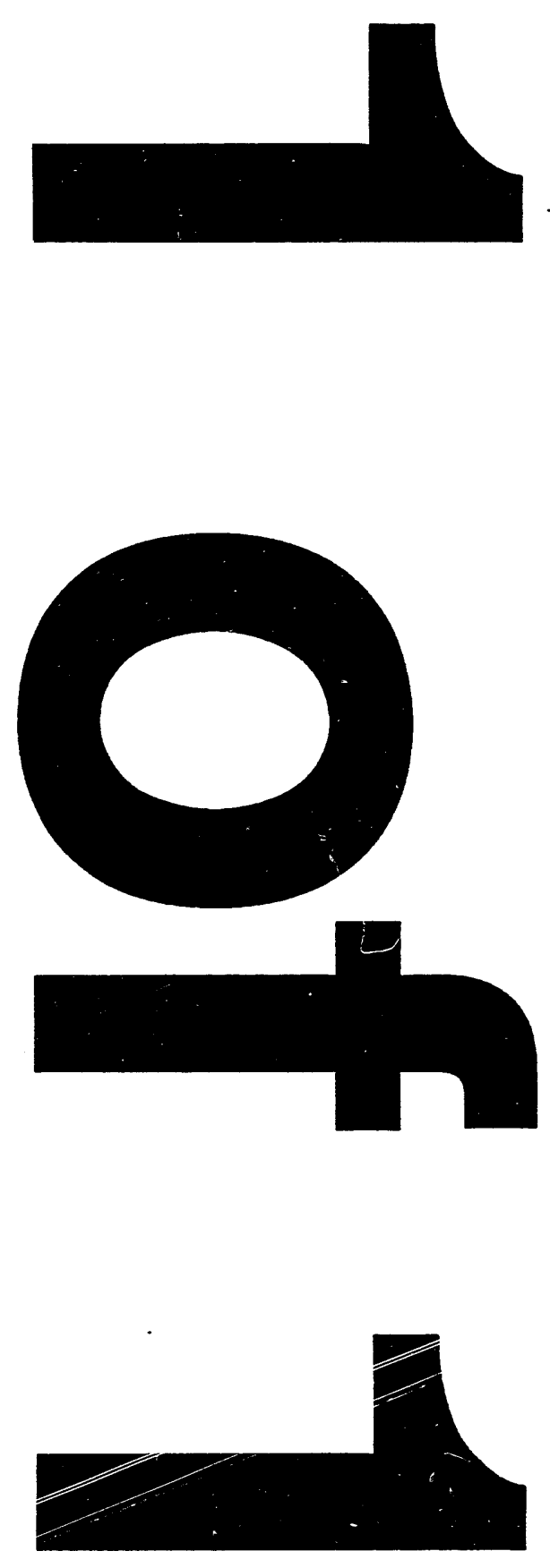


\title{
UPGRADE OF THE DIII-D VACUUM VESSEL PROTECTION SYSTEM
}

\author{
by \\ M.A. HOLLERBACH, R.L. LEE, J.P. SMITH, \\ and P.L. TAYLOR
}

This is a preprint of a paper to be presented at the 15th IEEE Symposium on Fusion Engineering, October 11-15, 1993, Cape Cod, Massachusetts, and to be printed in the Proceedings.

\author{
Work supported by \\ U.S. Department of Energy \\ Contract DE-AC03-89ER51114
}
GENERAL ATOMICS PROJECT 3466 OCTOBER 1993

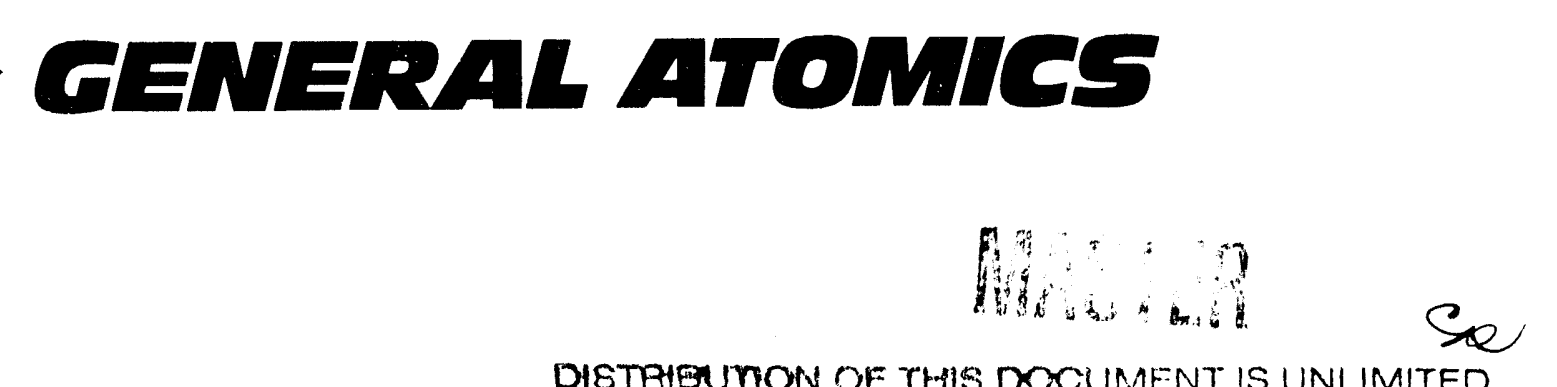




\title{
UPGRADE OF THE DIII-D VACUUM VESSEL PROTECTION SYSTEM
}

\author{
M.A. Hollerbach, R.L. Lee, J.P. Smith, and P. L. Taylor \\ General Atomics \\ P.0. Box 85608, San Diego, California 92186-9784
}

\begin{abstract}
An upgrade of the General Atomics DIII-D tokamak armor protection system has been completed. The upgrade consisted of armoring the outer wall and the divertor gas baffle with monolithic graphite tiles and cleaning the existing floor, ceiling, and inner wall tiles to remove any deposited impurity layer from the tile surfaces. The new tiles replace the graphite tiles used as local armor for neutral beam shine through, three graphite poloidal back-up limiter bands, and miscellaneous Inconel protection tiles. The total number of tiles increased from 1636 to 3200 and corresponding vessel coverage from $40 \%$ to $90 \%$. A new, graphite armored, toroidally continuous, gas baffle between the outer wall and the biased divertor ring was installed in order to accommodate the cryocondensation pump that was installed in parallel with the outer wall tiles. To eliminate a source of copper in the plasma, GRAFOIL gaskets replaced the copper felt metal gaskets previously used as a compliant heat transfer interface between the inertially cooled tiles and the vessel wall. GRAFOIL, an exfoliated, flexible graphite material from Union Carbide, Inc., was used between each tile and the vessel wall and also between each tile and its hold-down hardware. Testing was performed to determine the mechanical compliance, thermal conductance, and vacuum characteristics of the GRAFOIL material. To further decrease the quantity of high $\mathrm{Z}$ materials exposed to the plasma, the 1636 existing graphite tiles were identified, removed, and grit blasted to eliminate a thin layer of deposited metals which included nickel, chromium, and molybdenum. Prior to any processing, a selected set of tiles was tested for radioactivity, including tritium contamination. The tiles were grit blasted in a negative-pressure blasting cabinet using $37 \mu \mathrm{m}$ boron carbide powder as the blast media and dry nitrogen as the propellant. A 30 to $50 \mu \mathrm{m}$-thick layer was removed from the surfaces of each tile. The tiles were cleaned in an ultrasonic alcohol bath and vacuum baked to $1000^{\circ} \mathrm{C}$ prior to reinstallation. The installation of the graphite armor and gas baffle and the grit blasting of the tiles was performed in August 1992 through January 1993. Initial operational experience with the new armor system is summarized.
\end{abstract}

\section{INTRODUCTION}

The DIII-D device, a non-circular, low aspect ratio tokamak, has been operational since February 1986. Thus far, the physics program has been very successful in furthering the understanding of plasma current in attaining high beta and good confinement, and in demonstrating the importance of the divertor in attaining regimes of good confinement with neutral beam heating. In 1987 the floor, ceiling, and inner wall were covered with edgeclamped, graphite tiles. Operational experience with this armor was good, with no tile breakage to date. With the use of helium glow discharge cleaning and boronization, $\mathrm{H}$-mode and VH-mode confinement levels were achieved. To enhance the versatility of the device and increase the confinement, the Inconel outer vessel wall was recently covered with graphite tiles (Fig. 1), and the existing graphite tiles were cleaned to remove a layer of deposited metals, with the goal of reducing high $Z$ contaminants in the plasma.

\section{TILE DESIGN}

In January of 1992, two toroidal bands of graphite tiles adjacent to the ceiling were installed along with three poloidal backup limiters rurning from floor to ceiling. The project reported in this paper completed the outer wall coverage by adding 1211 new tiles that were

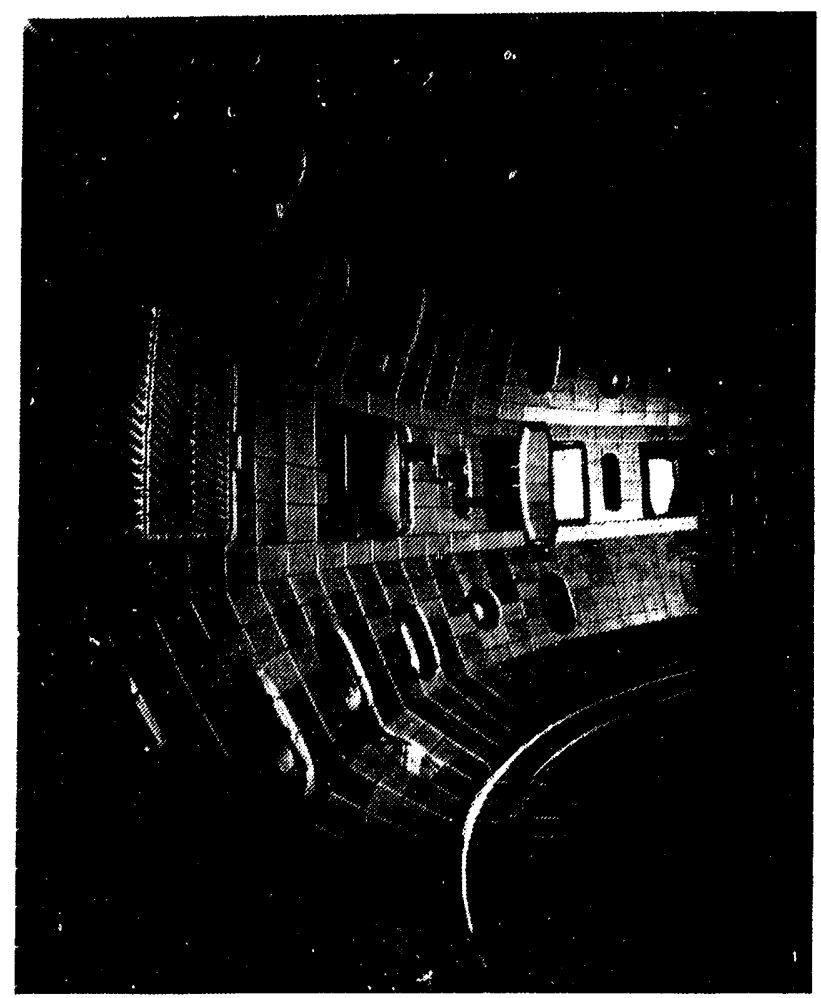

FIG. 1. DIII-D outer wall tiles, baffle plate tiles, ADP ring, and divertor floor.

Mamuscript received October 12, 1893. This is a report of work sponsored by the U.S. Department of Energy under Controct No. DE-AC03-89ER51114. 
installed during a five-month vent during late 1992 and early 1993. The average size of these tiles, which resemble a mushroom with one central stalk and a larger top surface, is $\sim 120 \times 190 \times 55 \mathrm{~mm}$ high. The hold-down hardware, consisting of a half-round bar with two sets of three Belleville washers stacked in series and two internal hex nuts, is located within the central stalk (Fig. 2). To eliminate design costs and simplify installation, the holddown hardware design used for the edge-clamped tiles installed in 1987 was also used for the outer wall tiles. Although the edge-clamped tile design has lower induced thermal-mechanical stresses $[1,2]$, it was not possible to use this design on the outer wall due to the many local interruptions (ports) in the wall, causing the hold down hardware to be exposed.

While the entire outer wall is now armored, it is not designed to be used as a limiter. Three back-up limiter bands running poloidally on the midplane band, $1 \mathrm{~cm}$ above the surrounding tiles, replace the three previouslyexisting poloidal limiters to define the plasma boundary.

In addition to the graphite tiles on the outer wall, 341 radiatively-cooled tiles armor 24 Inconel divertor gas baffle plates modified to accommodate the new cryocondensation pump [Fig. 3(a)] [3]. Previous plates were non-water-cooled Inconel 625 . The baffle plate tiles are smaller than those on the outer wall to minimize the plasma volume displaced, being $\sim 100 \times 130 \times 25 \mathrm{~mm}$ high. A new hold-down system, consisting of two halfround bars, each with two sets of two Belleville washers stacked in parallel, in series with two additional parallelstacked washers, and two internal hex nuts, was designed for these tiles [Fig. 3(b)]. The screws and warhers are attached to the baffle plate prior to installation, and the bars and nuts are mounted and fixed in the tiles by inserting a set screw through the back of the tile and into the bar to minimize loose parts in the vessel. The tiles are bolted in place after installation of the baffle plates is complete.

\section{GRAFOIL}

Copper felt metal was previously used asi a compliant heat transfer and load-distribution interface. between

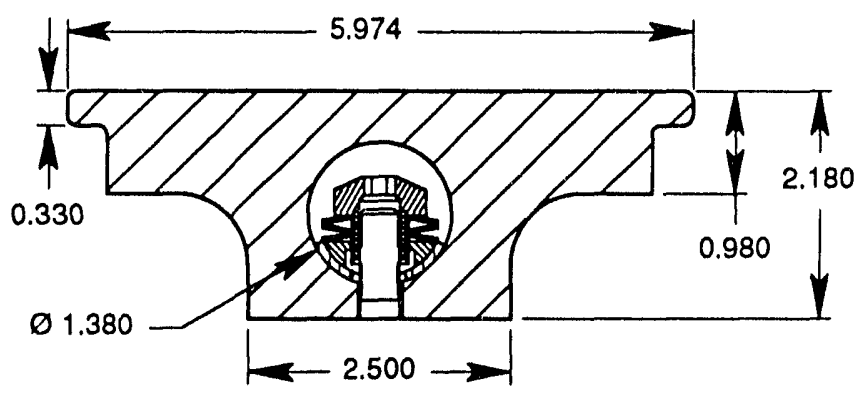

FIG. 2. Cross-section of a typical wall tile showing hold down hardware.

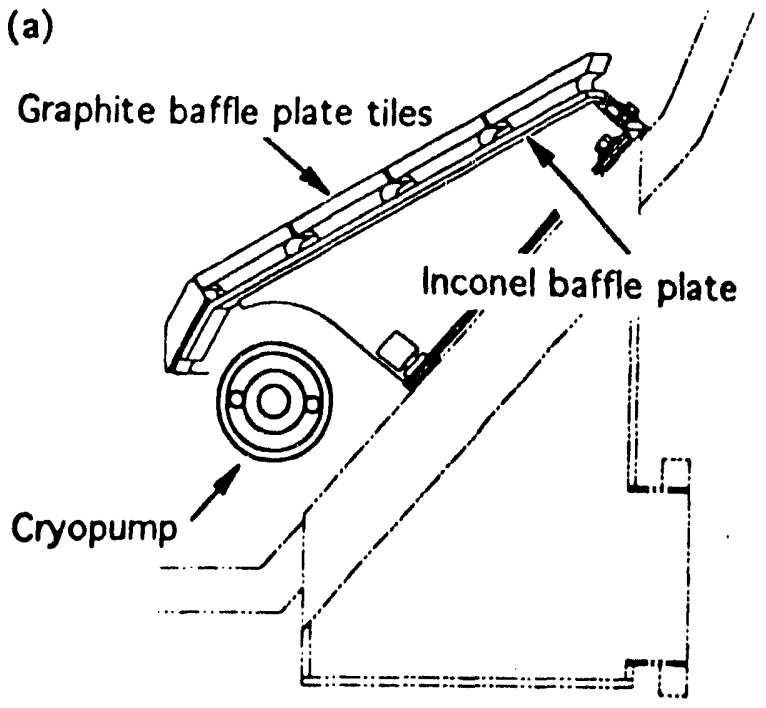

(b)

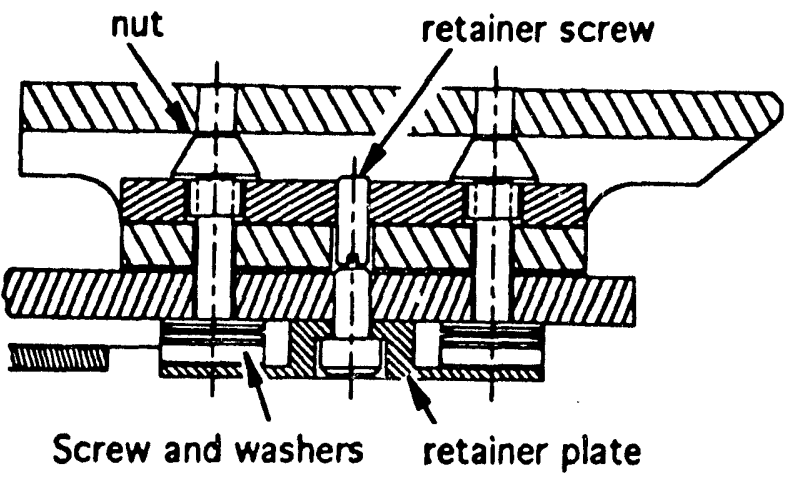

(c)

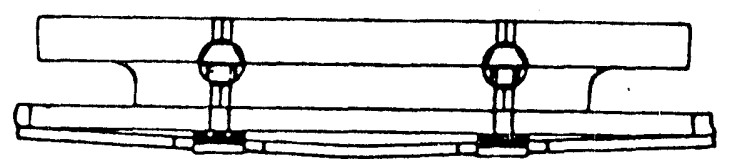

Fig. 3. (a) typical baffle plate in lower outside corner of DIII-D, (b) cross-section of a typical bar'se plate tile with mounting hardware, and (c) typical tile end view.

each tile and the vessel wall. Flakes from the felt metal caused disruptions or loss of data in approximately $20 \%$ of the plasma discharges. GRAFOIL, a flexible, exfoliated graphite material from Union Carbide, Inc. [4] was chosen as a candidate material to replace the copper. An investigation into the mechanical compliance, thermal conductance, and vacuum characteristics as well as a study of any impurities in the material was undertaken to determine if GRAFOIL was a suitable replacement material. The goal was to find a combination of density and initial thickness that would have compliance and heat transfer characteristics similar to the copper felt gaskets. After testing and analysis, $0.8 \mathrm{~g} / \mathrm{cm}^{3}$ dense material, initially $2 \mathrm{~mm}$ thick, was chosen for the gaskets 
between the tile foot and vessel wall. This combination resulted in an increase in stiffness of $60 \%$ and an increase of overall tile height (tile + gasket) of $0.35 \mathrm{~mm}$ over the copper material. Four $0.5 \mathrm{~mm}$ thick pieces were used between the tile and its hold-down hardware after single pieces of $2 \mathrm{~mm}$ thickness cracked while being bent around the half-round bar and attempts to form the $2 \mathrm{~mm}$ gaskets in a die or by rolling proved unsuccessful. Testing revealed that the thermal conductivity of the GRAFOIL is $\sim 0.10 \mathrm{~W} / \mathrm{cm}^{\circ}{ }^{\circ} \mathrm{C}$ at $350^{\circ} \mathrm{C}$ and is actually higher than that of the copper felt metal for temperatures below $350^{\circ} \mathrm{C}$. The results of the vacuum outgassing tests showed that the inclusion of the GRAFOIL gaskets would increase the outgassing rate of the vessel by approximately $6.5 \times 10^{-7}$ Torr $-\ell / \mathrm{sec}$, an acceptable amount. Detailed analysis using methods such as Neutron Activation and mass spectroscopy showed no impurity levels above 100 ppm except for silicon (500 ppm).

\section{TILE CLEANING}

To eliminate another potential source of high $Z$ plasma impurity, the 1636 graphite tiles previously used in the vessel, and not replaced by the new tiles, were taken from the vessel, identified according to their vessel location, and grit blasted to remove a deposited layer of impurities.

An extensive testing program was initiated at the beginning of this project to determine the constituents of the impurity layer deposited on the plasma-facing surface of the tiles and what method would work best to remove that layer. Through the use of Auger, EDX, and PIXE analyses, it was determined that the major impurities were nickel, chromium, molybdenum, (the major constituents of Inconel 625 , the vessel wall material), and bromine [5].

After researching other methods used and/or investigated at TFTR and TEXTOR for removing the deposited impurity layer such as sanding or milling, grit blasting was chosen as the easiest and most efficient method. A test program was undertaken to determine the parameters for the grit blasting. Boron carbide was chosen over silicon carbide and aluminum oxide as the blast media to minimize the effect of embedded material in the graphite tiles, as boron carbide is already used as a tile coating material in DIII-D. Of the candidate propellants, dry nitrogen was chosen over shop air and air from the clean, dry air system on site due to its availability, economy, and cleanliness. Tiles removed from the vessel during a previous vent were used as test samples. These tiles were grit blasted and analyzed for quality of impurity removal and depth of material removed. EDX analysis microphotographs of a grit blasted sample compared with an unblasted control sample are shown in Fig. 4. Because of the backscattering technique used, any impurity appears white in the photograph while the carbon appears black. After grit blasting, more than $90 \%$ of all impurities were removed from the tile surface.

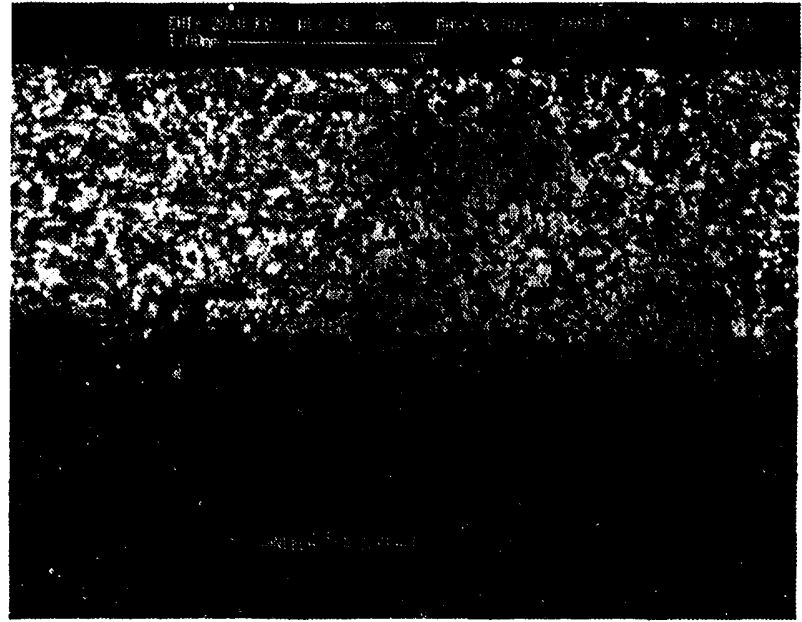

FIG. 4. EDX analysis microphotograph comparison of grit-blasted surface versus untreated surface.

A typical Auger surface analysis of before and after grit blasting is shown in Fig. 5. This analysis, which scans to a depth of a few microns, shows nickel, from the vessel wall, $\sim 1$ micron below the surface and boron on the surface from boronization techniques used on DIII-D. After grit blasting, all impurities are reduced to less than 5 relative atomic $\%$.

\section{CLEANING PROCEDURE}

After each tile was removed from the vessel wall, it was placed in a plastic bag marked with a prelabeled sticker identifying the tile's vessel location. The tiles were separated into lots to facilitate handling and tracking. The tiles were placed in a box outside the vessel and brought to the radiation survey area where they were measured for activation as well as tritium contamination. Because of the vacuum outgassing planned for the tiles, extensive testing was performed to ensure that the levels of removable tritium contamination were below the limits allowed by the State of California, $4000 \mathrm{DPM} / 100 \mathrm{~cm}^{2}$, and by the U.S. Department of Energy, 1000 DPM/ $100 \mathrm{~cm}^{2}$ [6]. Once released by Health Physics, the lots were brought to the grit blast area where each tile was permanently identified on the back surface with its vessel location using a vibra-etch tool, and grit blasted.

The actual tile grit blasting was performed in a negative pressure-blast cabinet using boron carbide $\left(\mathrm{B}_{4} \mathrm{C}\right)$ grit and a dry nitrogen propellant. The $\mathrm{B}_{4} \mathrm{C}$ had a nominal particle size of $37 \mu \mathrm{m}$. The blasting pressure was low, approximately $138 \mathrm{kPa}$, to minimize the likelihood of large material quantities being removed from a tile surface. An average depth of $30 \mu \mathrm{m}$ was removed from the plasma-facing surface of each tile with the upper limit being $50 \mu \mathrm{m}$. The blasting was a manual operation, taking approximately $3 \mathrm{~min}$ per tile. 

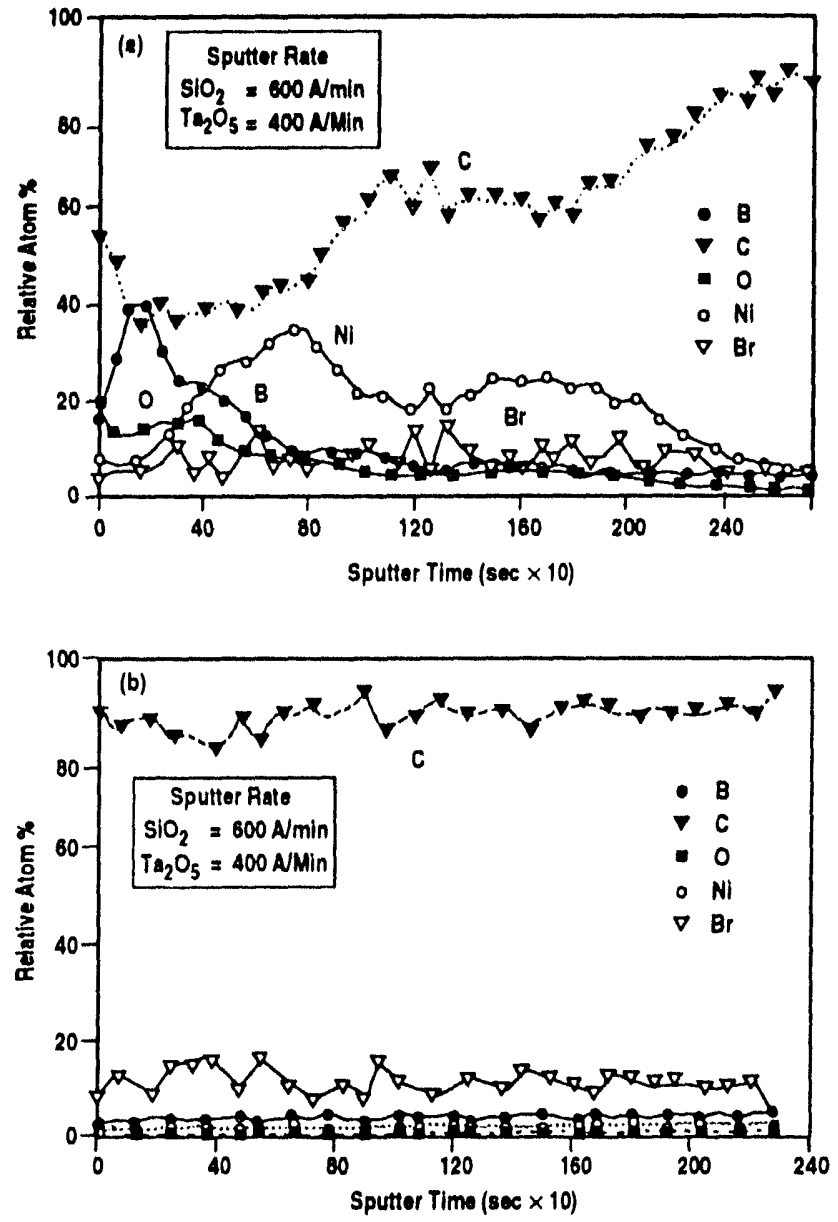

Fic. 5. Auger surface analysis performed (a) before grit blasting, and (b) after grit blasting.

\section{TILE INSTALLATION}

Both the new tiles received from machine shops and the grit blasted tiles were cleaned before their installation in the vessel. First, they were ultrasonically cleaned in a bath of 200-proof ethyl alcohol for 3 to $5 \mathrm{~min}$. Second, the tiles were baked at $1000^{\circ} \mathrm{C}$ for $4 \mathrm{hr}$ in one of three vacuum furnaces. The entire outgassing run took $\sim 18$ to $28 \mathrm{hr}$, depending on the number of tiles in a run. After cooling to $300^{\circ} \mathrm{C}$, the furnace was backfilled with argon. After further cooling to room temperature, each tile was sealed in a plastic bag until its reinstallation in the vessel. The entire cleaning process, including grit blasting and outgassing, took approximately 1080 manhours.

Prior to any tile installation on the outer wall, the mounting studs needed to be positioned and welded. Positioning of the studs was accomplished using clear mylar film templates with the stud outlines and port openings plotted on them. These templates were carefully aligned with the existing studs and port openings then taped in place. An impression at the stud center was made through the template, in the vessel wall using a center- punch. After removing the templates, the machined tip of a stud was then placed in this impression and the stud was electro-discharge welded. The integrity of each weld was checked by tightening a nut against a block to a specific torque value. The entire vessel wall was wiped down with ethyl alcohol, the gaskets put in place, and the tiles installed. Each tile was hand tightened then torqued to produce a clamping pressure of $345 \mathrm{kPa}$ for the baffle plate tiles, and $2 \mathrm{MPa}$ for the other tiles. Reinstallation of the floor, ceiling, and centerpost tiles was accomplished in a similar marner. Removal and installation of all the tiles took $\sim 3500$ manhours.

The only portions of the DIII-D outer wall not protected by armor tiles are 76 of the 83 port openings which comprise $10 \%$ of the total outer wall surface area. Seven of the port openings are covered with $0.95 \mathrm{~mm}$ thick $\mathrm{K}$-Karb carbon-carbon tiles bolted to Inconel backing plates to protect diagnostic leads in the ports.

\section{INITIAL OPERATIONAL EXPERIENCE}

Before plasma discharges were initiated, $47 \mathrm{hr}$ of baking the vessel to $350^{\circ} \mathrm{C}, 3.5 \mathrm{hr}$ of baking with helium Taylor discharge cleaning (TDC), and $3 \mathrm{hr}$ of helium glow discharge cleaning with baking were performed. Base pressures of $3 \times 10^{-8}$ Torr were achieved with a global leak rate of $3 \times 10^{-5}$ Torr- $\ell / \mathrm{sec}$. Overall the operational results have been very good. After starting plasma operations, the machine conditioned very rapidly, and on the 14th plasma discharge $\mathrm{H}$-mode plasma confinement was observed. Also VH-mode was reached for the first time in DIII-D with in unboronized wall. In addition, the first full toroidal fieid ohmic $\mathrm{H}$-mode was achieved.

In 1993 results to date, the sources of nickel, bromine, and copper have been reduced to very low levels. The impurity levels have been reduced such that the fraction of radiated power, $P_{\text {rad }} / P_{\text {in }}$, was 0.11 compared with 0.2 to 0.3 in 1991 and 1992 [7].

\section{REFERENCES}

[1] C.B. Baxi, P.M. Anderson, E.E. Reis, J.P. Smith, and P.D. Smith, "Thermal-streas analysis and testing of DIII-D armor tiles," in Proc. 12th Symp. on Fusion Engineering, pp. 231-234, 1887.

[2] J.P. Smith, P.M. Anderson, C.B. Baxi, E.E. Reis, and P.D. Smith, "Design of DIII-D armor tiles," in Proc. 12th Symp. on Fusion Engineering pp. 144-146, 1987.

[3] J.P. Smith, K.M. Schaubel, C.B. Baxi, G.L. Campbell, A.W. Hyatt, G.J. Laughon, et al., "Installation and initial operation of the DIII-D advanced divertor cryocondensation pump," this symposium.

[4] Union Carbide Co., Inc., P. O. Box 94637, Cleveland, OH 44101.

[5] R.L. Lee, M.A. Hollerbech, K.L. Holtrop, A.G. Kellman, P.L. Taylor, and W.P. West, "Surface impurity removal from DIII-D grephite tiles by boron carbide grit blasting," this symposium.

[6] P.L. Taylor, A.G. Kellman, and R.L. Lee, "Tritium in the DIII-D carbon tiles," J. Fusion Energy, in preas.

[7] G.L. Jackson, "Milestone report 1982 plasms operation with outside wall graphite tilea," unpublished. 

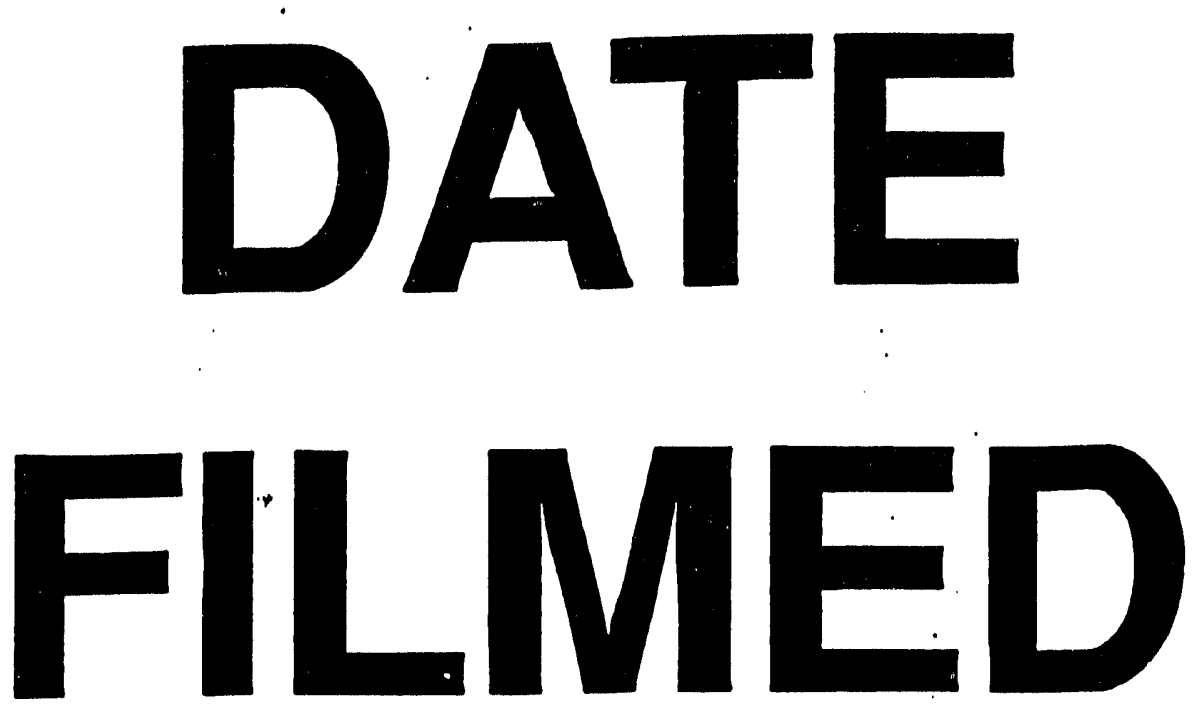

$12 / 10 / 93$
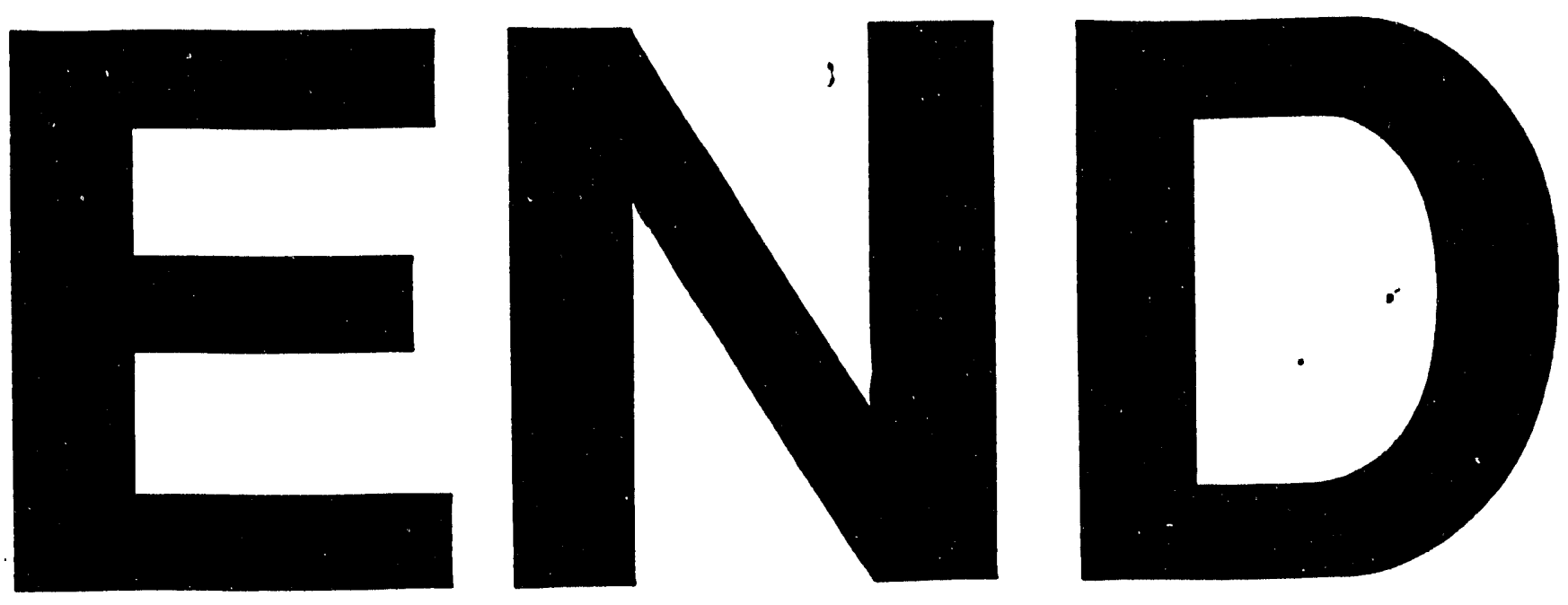
